\title{
Nepal's Telecom Sector Challenges Under WTO Rules
}

\section{Kailash Prasad Neupane}

Deputy Director of Legal Services, Nepal Telecommunications Authority

Nepal, situated along the southern slopes of the Himalayan mountain ranges, is a landlocked country, situated between India and China. Nepal occupies an area of 147,181 square kilometres and has about 27 million inhabitants. Topographically Nepal is divided into three regions: the mountain, hill and the terrace regions. About 83 percent of the country is rugged terrain and only 17 percent is flat land. Administratively the country is divided into five development regions, 14 zones, 75 districts 58 Municipalities and 3,915 Village Development Committees (VDC).

Each VDC is divided into 9 wards and municipalities into 9 to 35 wards.

However a new constitution is being drafted that will determine its federal structure.

Since it is very difficult and costly to build transportation infrastructures due to the rugged terrain, telecommunications services are of utmost importance for Nepal to serve the rural population. With the approach of the twenty-first century, it is realised that economic, social and cultural boundaries are disappearing. In this process, the movement of people and the trade of goods and services are dependent in Information and Communications Technology (ICT) that is based on telecommunications services. Thus exchange of information is a crucial fact.

\section{Telecom Sector Liberalization in Nepal}

After the restoration of the multi-party democracy in 1990, Government of Nepal adopted a liberalisation policy in communications sector by the formulation of
National Communication Policy 1992. In pursuant to the liberalisation policy, Government has decided to expedite the development of telecommunication services through private sector investments gradually. As result of such policy, telecom legislations were introduced. The Telecommunications Act, 2053 (1997), Telecommunications Regulations, 2054 (1997), Long Term Vision of Communication Sector, 2002 and Telecommunications Policy 2004 are the main legal and policy framework of telecommunications services in Nepal. Nepal Telecommunications Authority (NTA), separate regulatory body of Nepal in telecom sector has been constituted under the Telecom Act in order to make telecom service available throughout the country in a competitive manner and regulate the sector.

\section{Status of Telecom Sector in Nepal}

At present, the incumbent operator, Nepal Doorsanchar Company Limited (NDCL) the than Nepal Telecommunications Corporation (NTC) is operating local, domestic, long distance, international telephony, cellular mobile and internet service including ADSL in Nepal. Besides NDCL the regulatory authority, Nepal Telecommunication Authority (NTA) has issued one Mobile ${ }^{1}$ licence, two Basic ${ }^{2}$ and 2 rural $^{3}$ telecom ser-

\footnotetext{
${ }^{1}$ Spice Nepal Private Limited (SNPL) for GSM Mobile on September, 2004.

${ }^{2}$ United Telecommunication Limited (UTL) for a provision of basic telephone service based on Wireless in Local Loop (WLL) technology on 2002 and Nepal Satellite Telecommunications Private Limited (NSTPL) for providing basic services starting from the MidWestern Development Region in a technology neutral policy.

${ }^{3}$ STM Sanchar Private Limited (STM) for operating rural telecommunications services in the Eastern Development Region and to Smart Telecom Private Limited (STPL) for operating rural telecom services except Eastern Development Region of Nepal.
} 
vice licence to private telecommunications operators. ${ }^{4}$ Nepal is committed to improving telecommunications services and efficiency through competition and effective regulation of the telecommunication sectors. The current number of licenses in various telecom services and status of the sector is stipulated in the Annex-1 and Annex-2 respectively.

\section{Nepal in the WTO}

Nepal had applied for the membership of the GATT, 1947, the predecessor institution of WTO in 1989. Nepal obtained only an observer status in 1993. In 1997, Nepal converted its application for accession to the GATT to an application for membership to the WTO. In 1998, in accordance with WTO accession procedures, Nepal submitted a Memorandum of Foreign Trade Regime for circulation to all of the member states. A direct question and answer period between member states and the Nepalese Government followed until 1999. After the establishment of WTO in 1995, Nepal again applied to WTO secretariat in order to join the global village. Nepal had participated in a series of bilateral and working party meet with WTO member states.

Protocol of Accession of Nepal was adopted in the 5th WTO Ministerial Conference held at Cancun, Mexico on 11 September 2003. Nepal became 147th member state and the first LDC member to the WTO by negotiation since 23 April, 2004.

Nepal has commitment in 11 sectors and 70 subsectors on services including telecommunications services with conditions of:

(1) Incorporation of company in Nepal in accordance with Nepalese law is required and foreign equity participation ceiling is up to 80 per cent through joint venture.

(2) Intra corporate transferee is allowed up to $15 \%$ of total local employees as manager/executive/ specialist, maximum up to 10 years staying in Nepal;

(3) Membership of relevant professional organization is needed to serve in such professional service in Nepal etc.

Nepal had already opened up telecom sector for private and foreign investment before becoming member

\footnotetext{
${ }^{4}$ Present status of telecom service in Nepal is given in Annexe-1.
}

of WTO. After being member of WTO and scheduling the telecommunications service as specific commitment in its protocol of accession, the subject became a multilateral agreement and global issue. Obviously, Nepal has agreed to abide by its obligation through the agreement. Nepal also agreed to adopt the Telecommunications Reference Paper in addition to the specific commitments. Now Nepal is obliged to create an environment for the development of institutional arrangements as stipulated in the Reference Paper.

\section{Nepal's Commitment on Telecommunication Sector in the WTO}

While Nepal submitted its application to the WTO there was a list of a few sectors for opening up. After the working party and bilateral meet the list of services for opening up for the WTO provision was increased. Many member states advised to open telecommunications services too. So, Nepal submitted its telecommunication services in line with the then Telecom Policy, 1999.

The telecommunications services proposed by Nepal to the WTO and adopted by the member states of WTO are as follows:

\section{Basic Telephone Service}
a. Local telephone service
b. Domestic telephone service
c. International telephone service
d. Telex service
e. Domestic and international telegraph services

2. Mobile Telephone Service

3. Value Added Services of Telecommunications
a. Internet including e-mail
b. E-mail
c. Voice Mail
d. Video text
e. Fax Mail
f. VSAT
g. Audio Conference
h. Pay Phone
i. Pre-paid Calling Card
j. Local, Long Distance and International Data Communication
k. Radio Paging
1. Trunk Mobile. 
The Protocol of Accession states that 'No limitation on number of service providers will exist by January 2009'. Commercial presence, one mode of service trade rule is accepted and foreign equity participation through joint venture is opened up to 80 percent. In all above mentioned telecommunication services for terms of Limitation of Market Access and on Mode of Supply (1) Cross-Border Supply (mode 1) and (2) Consumption abroad (mode 2 ) are fully committed. These two modes have been specified indicating the word 'None' in the Nepal's service commitment schedule. Mode (3) Commercial Presence is permitted with completing some conditions as indicated in the Horizontal commitment. The commitment indicates 'None, except as indicated in horizontal commitment'. In mode (4) Presence of Natural Presence, indicates the same language i.e. 'None except as indicated in the Horizontal commitment'. So Nepal has no full commitment in modes 3 and 4. The schedule states None, except. ., and Unbound, except. .., in the column 'Limitation on Market Access', respectively.

Nepal has committed itself for 'Limitation on Market Access' for Basic Telecommunication Services that is opened the market from 1st January 2009 and number of services providers is unlimited from 2009 onwards. Foreign equity participation through joint venture with up to 80 per cent is legally recognized. Foreign nationals can enter into Nepal to work as consultant, only in that area which is not available in Nepal for 90 days.

On the column of Limitations on National Treatment, Nepal states that the majority of the members of the Board of Directors of a joint venture should be Nepalese Nationals. Nepal's schedule on telecommunications services undertakes additional commitments in the Telecommunications References Paper as specific commitments. The Reference Paper also adds some extra burden to Nepal.

The Telecommunications Reference Paper states for 1) Competitive safeguards 2) Interconnection 3) Universal service 4) Public availability of licensing criteria 5) Independent Regulators and 6) Allocation and use of scarce resources.

\section{Challenges}

After accession into WTO and commitment on telecom services arises some policy level and functional challenges for Least Developed Countries (LDCs) like Nepal. These may be indicated as follows:
- LDCs would not have done enough research due to constraints of budget and skill manpower. So, LDCs like Nepal may not be able to identify sectors of competitive advantage. But they are forced to commit in the name of harmonization between member country legislation to become member of WTO.

- The governments of LDCs may need to change national policies time and again by various reasons but after accession to WTO there will be little room for flexibility for such policy changes.

- There are so many institutional requirements under WTO agreement, which may not be fulfilled by the member states in time.

- LDCs do not generally have sufficient and developed human resources in all sectors, like telecommunications, technology etc. They may not be able to comply with WTO provisions and compete with other member states.

Apart from the local level difficulties there are some global level difference in policy and approaches of regulation. These can be summarized as below:

WTO service classification is changing due to the changes of technology. S0, WTO service sectoral classification list MNT. GNS/W/120 of 10 July 1991 is different from the present one. Under the WTO classification, telecom services are dividing in to two broad categories. (1) Basic Telecommunications Services, voice telephone service, telex, telegraph, mobile telephone service etc and (2) Value Added Telecommunications Services. Mobile telecom is included in the Basic telecom services. But the original classification MNT GNS/W/120 is not been changed. This is the reason why Nepal still differentiates between Basic and Mobile services.

There are some regulatory issues under the mode of supply formula. It is difficult to regulate under such formula due to changing nature of the service, development of ICT technology and convergence. Here are some findings of such difficulties, such as;

- Regulatory regime is not often mode-specific.

- Supply of services comes under multiple regulatory regimes.

- Physical distance between regulators and suppliers creates problem in the part of enforcement of regulations and Jurisdictional issues

- Restriction on means of supply (VOIP is not opened by all countries.) 
Table 1.1 Available voice Telephony Services

\begin{tabular}{|c|c|c|c|c|c|c|}
\hline Services & $\begin{array}{c}\text { Nepal } \\
\text { Doorsanchar } \\
\text { Company } \\
\text { Limited } \\
\text { (NDCL) }\end{array}$ & $\begin{array}{l}\text { United } \\
\text { Telecom } \\
\text { Limited } \\
\text { (UTL) }\end{array}$ & $\begin{array}{c}\text { Spice } \\
\text { Nepal } \\
\text { Pvt. } \\
\text { Ltd. } \\
\text { (SNPL) }\end{array}$ & $\begin{array}{c}\text { STM } \\
\text { Telecom } \\
\text { Sanchar } \\
\text { Pvt. } \\
\text { Ltd. } \\
\text { (STM) }\end{array}$ & Others & Total \\
\hline Fixed & & & & & & 807,340 \\
\hline Wireline(PSTN) & 556,080 & - & - & - & - & 556,080 \\
\hline Wireless(WLL) & 179,543 & $67,637^{*}$ & & 4,080 & & 251,260 \\
\hline Mobile & & & & & & $5,080,477$ \\
\hline GSM & $2,695,505$ & - & $1,856,323$ & - & - & $4,551,828$ \\
\hline CDMA(Sky & 528,649 & - & - & - & - & 528,649 \\
\hline \multicolumn{7}{|l|}{ Phone) } \\
\hline Others & & & & & & 68,602 \\
\hline Limited Mobility & - & $66,404^{*}$ & - & - & - & 66,404 \\
\hline GMPCS & - & - & - & - & 1,517 & 1,517 \\
\hline WCDMA (G3) & 681 & - & - & - & - & 681 \\
\hline Total & $3,960,458$ & 134,041 & $1,856,323$ & 4,080 & $\mathbf{1 , 5 1 7}$ & $59,56,419$ \\
\hline \multicolumn{7}{|l|}{ Tele-Density } \\
\hline Services & & & & \multicolumn{3}{|c|}{ Penetration Rate \% } \\
\hline Fixed & & & & \multicolumn{3}{|l|}{$2.93 \%$} \\
\hline Mobile & & & & \multicolumn{3}{|l|}{$18.47 \%$} \\
\hline \multicolumn{4}{|c|}{ Others (Limited Mobility, GMPCS etc.) } & \multicolumn{3}{|l|}{$0.25 \%$} \\
\hline \multicolumn{4}{|l|}{ Total } & \multicolumn{3}{|l|}{$21.65 \%$} \\
\hline
\end{tabular}

${ }^{*}$ Data as of Chaitra, 2065.

Note: Projected population for 2009 Central Bureau of Statistics 2,75,04,280.

- Data privacy/protection laws/regulations are not introduced in most of the LDCs. Thus legal remedies may not be available and if available would be different from countries to countries.

- Problems on definition of Computer and related services could create possible overlap between telecommunication services and computer services.

\section{Hence the following questions should be discussed and addressed by each member countries}

- Are mode-specific regulatory disciplines applicable and necessary for Telecommunications Trade in the convergence era?

- Is it technically feasible to regulate cross-border services? Whereas consumption abroad, like ILD call, prepaid calling card, GMPCS are difficult to enforce regulatory measures from originating state?

- Are there differences between Mode 1 and Mode 2 ?

- Is it necessary for cross-border services to be subject to the same regulatory requirements and standards as applied to services supplied domestically?
- On-line information and/or data processing CPC 843 (including transaction processing) is listed under telecommunication services and the same CPC code is stipulated for data-processing services, (CPC 843) under Computer and related services. So, if regulated separately those services could raise regulatory ambiguity?

- How uncertainty in regulation due to convergence of broadcast, telecommunications and ICT can be minimized?

\section{Conclusion}

All the commitments made by LDCs may not be fulfilled in time. Further more; technology may not be in status quo situation. The rapid development of technology and use of ICT always demands advanced forms of the technology. Telecom, broadcasting and ICT convergence in technological and regulatory aspects were not perceived at the time of NGBT/GBT. Now, convergence has been taken place and the 21 st century grossly demanded such convergence. Thus, WTO trade rule on converged nature services like Broadcasting, Telecommunications, and ICT has to be reviewed and recommend to the ITU and WTO in this matter. Exchange of knowledge and regulatory experience sharing would help LDCs to address the challenges in a more uniform and holistic manner. 


\section{Annex-1}

List of existing Licenses in the different types of Telecommunications Services:

\begin{tabular}{cll}
\hline S. No. & Services & Number of licensees \\
\hline (a) & Basic Telephone & 3 \\
(b) & Cellular Mobile Telephone & 2 \\
(c) & Internet (with e-mail) & $38+1$ Rural \\
(f) & Network Providers & 8 \\
(g) & VSAT Service Users & $90+3$ Rural \\
(h) & Video Conferencing & 1 \\
(i) & GMPCS & 3 \\
(j) & Rural Telecom Service & 2 \\
(k) & Limited Mobility Service & 12 \\
& Total & 163 \\
\hline
\end{tabular}

Source: NTA internal data sheet.

\section{Annex-2}

1. Nepalese Telecom Statistics at a glance (as on 13 April 2009) (see Table 1.1 on previous page.)

Table 1.2 Data Services

\begin{tabular}{lcccc}
\hline \multirow{2}{*}{ Services } & \multicolumn{3}{c}{ Subscribers } & \multirow{2}{*}{ Total } \\
\cline { 2 - 4 } & NDCL & UTL & ISPs & \\
\hline Internet & 83,420 & $6,932 *$ & 61,000 & $\mathbf{1 5 1 , 3 5 2}$ \\
ADSL $^{1}$ & 15,560 & & & $\mathbf{1 5 , 5 6 0}$ \\
Total & 98,980 & $6,932 *$ & 61,000 & $\mathbf{1 6 6 , 9 1 2}$ \\
\hline
\end{tabular}

*Data as of 13 April, 2009

${ }^{1}$ Speed $=$ More than 64 Kpbs.
Table 1.4 Public Call Centers (PCO)

\begin{tabular}{lc}
\hline Services & Subscribers \\
\hline Rural PCO & 1,885 \\
$\begin{array}{l}\text { No of Unserved Village Development Commit- } \\
\text { tee (VDC) Telephone Service }\end{array}$ & 420 \\
$\begin{array}{l}\text { No. of Served Village Development Committee } \\
\text { (VDC) }\end{array}$ & 3,495 \\
\hline
\end{tabular}

Source: http://www.nta.gov.np/articleimages/file/NTA MIS_26.pdf. ${ }^{1}$ Spice Nepal Private Limited (SNPL) for GSM Mobile on September, 2004.

${ }^{2}$ United Telecommunication Limited (UTL) for a provision of basic telephone service based on Wireless in Local Loop (WLL) technology on 2002 and Nepal Satellite Telecommunications Private Limited (NSTPL) for providing basic services starting from the Mid-Western Development Region in a technology neutral policy.

${ }^{3}$ STM Sanchar Private Limited (STM) for operating rural telecommunications services in the Eastern Development Region and to Smart Telecom Private Limited (STPL) for operating rural telecom services except Eastern Development Region of Nepal.

${ }^{4}$ Present status of telecom service in Nepal is given in Annexe-1. 